\title{
Emotional Labor between Supervisors and Subordinates: Literature Review and Future Research
}

\author{
Meng Li', Linli Liang² \\ ${ }^{1}$ School of Business Administration, South China University of Technology, Guangzhou, China \\ ${ }^{2}$ School of Public Administration, South China University of Technology, Guangzhou, China \\ Email: victorleescut@163.com
}

Received 4 January 2016; accepted 22 January 2016; published 25 January 2016

Copyright (C) 2016 by authors and Scientific Research Publishing Inc.

This work is licensed under the Creative Commons Attribution International License (CC BY). http://creativecommons.org/licenses/by/4.0/

c) (i) Open Access

\begin{abstract}
This paper discusses the trend of the emotional labor research object from the external customers to the internal customers of the organization, and separately reviews the study of subordinates' emotional labor on supervisors and the study of supervisors' emotional labor on subordinates. Finally, the paper identifies several future research directions, including the measurement of emotional labor between supervisors and subordinates, the research of the relationship between positive leadership behavior and subordinates' emotional labor, and the integrated research between supervisors' and subordinates' emotional labor.
\end{abstract}

\section{Keywords}

\author{
Emotional Labor, External Customers, Internal Customers, Leadership Behavior, Positive \\ Leadership
}

\section{Introduction}

Emotional labor refers to the employees who express and adjust their emotions according to the way expected by the organization in their interpersonal interaction of the work. Emotional labors, the concept officially being put forward by Hochschild in 1983, have been largely researched by later scholars, which has accumulated fruitful results, including from the initial qualitative research to empirical research later on, from the psychological level of personal emotion research to organizational behavior study of workplace emotional labor research. These studies mainly include: the expansion of the emotional labor definition, dimensions and discussion, updating and improving the scale, the construction of theoretical framework, enriching the research methods, the 
antecedent and consequence variables of emotional labor research, etc. [1]. These studies not only have a certain theoretical significance, but also provide a lot of guidance for the management practice.

In previous studies, most scholars' research objects are limited to the first-line service personnel. However, Hochschild think emotional labor also exists to customers within the organization (such as bosses, colleagues and subordinates). Some scholars also called for research on emotional labor in the internal organization, especially on the interaction between the upper and lower levels [1]. In later studies, some scholars have broadened the scope of emotional labor research in the aspect of subordinates' emotional labor on their supervisors. However, Humphrey think supervisors also need the emotional labor on subordinates. So they proposed concept "leadership through the emotional labor on subordinates between the upper and lower levels", which has opened up a new research direction of emotional labor in the future [2].

This paper separately reviews the study of subordinates' emotional labor on supervisors and the study of supervisors' emotional labor on subordinates. Finally, the paper identifies several future research directions, including the measurement of emotional labor between supervisors and subordinates, the research of the relationship between positive leadership behavior and subordinates' emotional labor, and the integrated research between supervisors' and subordinates' emotional labor.

Hochschild first proposed the concept of emotional labor in 1979, and formally gave the definition of the word in 1983, which refers to "Staff is committed to emotional management, in order to create facial expressions or body movements other people are willing to see in public, and emotional labor can be sold for wages, therefore it has exchange value" [1]. It is important to note that this definition was put forward by Hochschild after detailed analysis of the work was conducted in the frontline service of the flight attendants. In the late 1980s and early 1990s, Rafaeli and Sutton made a series of qualitative research on emotional labor in different industries, which caused the scholars' research interest. Later, Hochschild further expands the definition of emotional labor. She believes that emotional labor is across all walks of life, including both the external customers and internal customers (like colleague, boss, subordinates) [1]. Grandey, from the perspective of emotional labor intrinsic psychological processing, proposes that emotional labor is the necessary psychological adjustment process put forward for expressing emotions group expects [3]. Similarly, according to Diefendorff and Gosser, emotional labor is defined as "employees continue to monitor whether there is a difference between their own emotions performance and organization performance rules, and try to adopt a certain emotion regulation strategies to reduce the differences of psychological process" [4].

Although scholars have put forward a variety of similar definitions, the concept of emotional labor has three obvious characteristics: Firstly, the interpersonal behaviors occur in work; Secondly it needs to follow certain rules, which can be written, also exists implicitly in interpersonal behaviors; Thirdly, the mechanism of emotional labor is emotion regulation. Zongyou Wu (2013), the scholar, Launched a heated discussion from the perspective of the above three characteristics, which finally concluded that emotional labor was applicable to the interaction between higher and lower levels of the organizations [5]. Therefore, this paper holds that, whether from Hochschild's definition of emotional labor, or from the other scholars' arguments, the concept of emotional labor applies to organizations in the process of interaction between supervisors and subordinates, and the study should be conducted within and outside the organization.

Emotional labor strategy is the most core content of emotional labor, even Grandey and Diefendorff think emotional labor strategy refers to the emotional labor [6]. Hochschild divides emotional labor into the surface acting strategy and deep acting strategy. The surface acting strategy is a kind of external surface disguise, which refers to the personal efforts to change the external visible surface emotions, to cater to the demand of emotional expression. However, the emotions they really want to express and its inner emotions are not consistent; Deep acting is a kind of disguise from inside out, which refers to make efforts to match the real emotional experience with organizational expectations through a variety of emotional management if there is a difference between the personal inner true feelings and work roles or organizational expectations [7]. Although there are various scholars who proposed the classification of many emotional labor strategies from different angles, later scholars mainly focus on this two path divisions in empirical research.

\section{The Evolution of Emotional Labor Concept in Organizations}

\subsection{The Limited First-Line Service Personnel Research}

Although Hochschild, according to the study of the first-line service personnel, put forward the concept of emo- 
tional labor, he did not believe that the study of emotional labor is only limited to the frontline service process, which, however, become a kind of common phenomenon in management research at home and abroad [1]. Ashforth and Humphrey pointed out that the foreign researches of emotional labor are too limited to the first-line staff, and more attention should be paid to the interactions among the members of the organization; Humphrey, Wu and Hu also agree that we should pay attention to the emotional labor research between supervisors and subordinates [8] [9]; Inputting the word "emotional labor" into the CNKI (National Knowledge Infrastructure of China), according to the search method of full text and selecting the subject categories from the psychology and the enterprise economic papers, you will eventually get 172 papers of emotional labor theme in journals, of which 126 study object in Ph.D. Dissertation are limited to the first-line service personnel, the remaining 46 article involved in the interaction between the supervisors' and the subordinates' emotional labor research, such as Liu Chao survey the data of service-oriented businesses to study, the relationship among the leadership style, emotional labor and organizational citizenship behavior [10]. Liu Chao also studied the relationship between emotional labor and the role of the employee organizational identification [11]; Around the theme of emotional labor, Xupei Li and Wang Zhen studied the relationship between transformational leadership and emotional labor strategy [12]. In conclusion, the study of emotional labor is mostly limited to the first-line service personnel, and the emotional labor research on the upper and lower levels within the organization still needs to be increased.

As to the reason for this phenomenon, barger and Grandey considered first-line service personnel's work involves emotions on customer transmissions, which will directly influence the customer's evaluation of the service [13]. Scholar Wu (2008) thinks that there are three main reasons for this phenomenon: Firstly, as stated above, Hochschild put forward the concept of emotional labor according to the service research of first-line flight attendant, of which there are many discussions of emotional expression and regulation about the works of flight attendant service; Secondly, because of the frequent contact between first-line service personnel and customers, emotional labor is relatively important to the requirement of the mood. It does matter whether the firstline service personnel show appropriate emotions at the appropriate time directly affect the personal service quality and customer evaluation in the process of service. Therefore, scholars often put the first-line service personnel as a typical object of emotional labor research. Thirdly, some important theoretical model of emotional labor are mostly based on the first-line service personnel's work [14], therefore some high quality papers published in top journals are so influential that some more scholars are keen to study this subject.

\subsection{Internalization of Emotional Labor}

Academic circles in foreign countries have very early called for emotional labor research to make the shift from the first-line service contact to the internal organization, especially emotional labor between supervisors and subordinates. Most scholars believe that it will hinder the development of emotional labor research if emotional labor research object is limited to the first-line service personnel. Actually, Hochschild, as to the definition of emotional labor, thinks that other social relations can also lead to emotional labor, beyond the first-line service work [15]. Hochschild proposed that an object of emotional labor can also include the internal customers, such as colleagues, superiors and subordinates [1].

After Hochschild formally putting forward the concept of emotional labor, Morris and Feldman built the theoretical framework of emotional labor based on service work, and they emphasized that each position within the organization also contains the rules of emotional expression and regulation of specification, so the concept of emotional labor can be applied to internal and external organization [16]. The scholars Huijun Zhao and Yanping Xi also thinks, the research object of emotional labor has significantly "window" characteristics to the service-oriented enterprise employees, but the scholars need to notice that emotional labor exists in various groups, such as colleagues, supervisors and subordinates [17].

\section{Emotional Labor between the Upper and Lower Levels of the Organization}

Generally speaking, because the supervisors relatively have advantages over subordinates in power and status, subordinates is usually expected to show emotion labor on supervisors, in order to facilitate the establishment of a harmonious relationship between the upper and lower levels, to make work smoothly. However, Humphrey pointed out that, in addition to subordinates' emotional labor, the supervisors also need to commit an act of emotional labor, because supervisors need to strive for the positive reaction of subordinates through individual 
emotional expression, in order to achieve the benefit of the teamwork and organizational objectives [18]. Therefore, it formed two camps in the research on emotional labor between the upper and lower levels of the organization: one part of this research is concentrated on subordinates' emotional labor [19]-[21], and another part of this research concentrated on supervisors' emotional labor [22] [23].

\subsection{Subordinates' Emotional Labor on Supervisors}

In the study of the interactive process of emotional labor between the supervisors and the subordinates, subordinates' emotional labor get more research attention, which is mainly because the supervisors' social status rank higher, and lower social side often needs emotional labor to avoid disadvantages; In addition, in their daily work, subordinates need to work according to the instructions of their supervisors, and the subordinates cater to the supervisors' command through the emotional labor, which is the duty for subordinates [17].

Rafaeli and Sutton launched the qualitative research on emotional labor, and later scholars follow the theme to carry out the qualitative research. The Wichroski's study found that the work of the Secretary involved emotion regulation, which needs to follow more emotional acting rules [24]. Lively’s study found assistant lawyer need to adjust personal emotions according to the principle of expertise, obedience and care, thus allowing themselves to be able to be eligible subordinate [25].

We all know that the negative leadership behavior of supervisor is easy to cause the subordinate emotional responses, especially emotional labor [26]. And abusive management in recent years has become a research hotspot, so many scholars combine abusive management with subordinates' emotional labor research. Grandey attempt to testify the correlation between supervisor's verbal abusive behaviors and subordinate's emotional labor relationship. The results show that there is no significant relationship [27]. Wu believes that the reason is that there are some problems about Grandey's scale. Grandey's scale is used to measure customer service process of emotional labor, which may not suitable for measuring the relationship between higher and lower levels of emotional labor. To solve this problem, Wu measured the subordinates' emotional labor, and found that the abusive management playing an intermediary role through the subordinates' emotional labor, namely the higher authority Subordinates perceived, the more emotional labor abusive of management led subordinates to invest [19]. Carlson, who also did the corresponding research, found that surface acting playing an intermediary role in the relationship between supervisors' abusive management and subordinates' job burnout, but Carlson ignored the path of the deep acting in the study [20]. In view of this, Wu and Hu's studies, based on action theory, have found that, abusive management has positive correlation with the subordinate's surface acting, and has a negative correlation with subordinate's deep acting, which indicates that outgoing character will regulate relationship between abusive management and two kinds of emotional labor strategy [28].

Authoritarian leadership is a general leadership style in Chinese cultural context, and easily leads to subordinates' emotion regulation effect, so this subject has also been a hotspot by later scholars. Jingyi Xu found that, the more the negative perception subordinates had, the more emotional labor the subordinate will use to inhibit the negative emotion when the supervisors are more inclined to authoritarian leadership style [29]. Wu found that supervisors' authoritarian leadership can positively predict subordinates' emotional exhaustion, and negatively predict subordinates' job satisfaction, of which emotional labor plays an intermediary role in these two relations. This paper also found that subordinate personal tradition will regulate the relationship between authoritarian leadership and subordinates' surface acting, deep acting. Personal tradition not only weaken positive relationship between authoritarian leadership and subordinates' surface performance, but also enhance the possibility of subordinates' deep acting strategies which subordinates will take in the face of authoritarian leadership style [29].

\subsection{Supervisors' Emotional Labor on Subordinates}

As early as Hochschild put forward the characteristics of emotional labor, it is pointed out that the leadership also needs to carry out emotional labor. Later, Humphrey proposed the concept of emotional labor in subordinate, and opened up a new direction for the study of emotional labor. Humphrey suggested that "through the emotional labor to carry out the concept of leadership", supervisors show appropriate external mood so as to exert some influence on subordinates' emotion, motivation and job performance, and deep acting is better than surface acting. Johnson's study also found that supervisors' emotional labor is closely related with subordinates' morale and job performance [30]. 
In the emotional labor research of supervisors', most scholars stay in reviewing the theme of emotional labor, but there also have a small amount of empirical research. Liu Chao studied the influence of supervisors' emotional labor on transformational leadership and organizational identification in the context of Chinese culture, and empirical research found that surface acting had negative correlation with organizational identity, while supervisors' deep acting and sincere acting had positive correlation with organizational identity, of which transformational leadership plays the part of the intermediary role in relationship between organizational identity and the supervisors' emotional labor [31].

\section{Conclusions and Recommendations}

\subsection{Future Research of Concept Measurement}

In the empirical research, the accuracy of the measurement scale has a direct impact on the scientific research results. Therefore, the scale development of a good reliability and validity is very important. As to the theme of emotional labor between higher and lower levels of the organization, although a certain empirical researches have been accumulated, this paper thinks that measure tools used by scholars are questionable and to be improved, because most scholars have used the scale originally developed from first-line service personnel. As mentioned earlier, there are some differences between the first-line service personnel of emotional labor and organizational emotional labor, of which its connotation may also has the difference, and may affect measurement accuracy with the kind of measure scale. Friesen and fish used the measure scale adapted from the Grandey's scale, which is used to measure emotional labor behavior of the school administrative personnel; Although Chao Liu, Jingyi Xu and Jieyun Zan used the Peijun Wu's scale, whose validation was verified and testified appropriate for the situation of China, the scale is still based on the Grandey's scale, of which the emotional labor practices were used to survey first-line service personnel. Some items such as "when I face the customer, not just feel happy in appearance, also in the heart”, may not be appropriate for being used to measure the supervisors' emotional labor on subordinates.

Zongyou Wu proposed that we could collect emotions events and resulting labor behavior between the supervisors and subordinates by the method of observing the behaviors. This bottom-up induction method has certain advantages, which are beneficial to develop emotional labor scale. Future research can refer to this proposal for scale development.

In addition to the negative leadership behavior, scholars should also pay attention to the relationship between positive leadership behavior and subordinates' emotional labor research. There is a little research in this aspect, such as Liu Chao's research involves the relationship among the transformational leadership, subordinates' emotional labor and organizational citizenship behavior [11]. When leaders show the positive behavior, such as support, trust and respect, will subordinates reduce the emotional disguise and adjustment and show true self because of the leader's positive performance? Or, because of the leaders' trust, care and understanding, subordinates are expected to positive emotional response to the leadership. Whether will this make the subordinate show a positive mood to take more emotional labor practices? These questions are yet to be further researched in the future.

\subsection{Future Research of the Relationship between Positive Leadership Behavior and the Emotional Labor of Subordinates}

From a subordinates' emotional labor research review we can see, due to the supervisor's negative leadership behavior, it is likely to cause subordinates' emotional labor and emotional regulating [7]. Therefore, many scholars have studied the relationship between abusive management and subordinates' emotional labor. At the same time, the relationship between authoritarian leadership and subordinate's emotional labor is a hotspot in the research for scholars, and most of the results are negative [29]. According to fiedler contingency theory, there is no absolute right and wrong way in the leadership, and the effectiveness of leadership is situational attribute and determined by the characteristics of subordinates [17]. While authoritarian leadership emphasizes the control of the subordinates and authority, it does not necessarily lead to negative effects, according to the study of Zongyou Wu and Hongyi Liao [32]. And this paper holds that, the study of relationship between the negative leadership behavior and subordinates' emotional labor should adhere to double path: the surface acting and deep acting, striving for further refine research, rather than only consider the emotional labor as a general concept in 
research.

\subsection{Recommendations}

Previous studies on the theme of emotional labor habitually split the relationship between supervisors' and subordinates' emotional labor. Epitropaki's study found that the supervisors' emotional labor will affect subordinates' emotional labor to through the perception of transformational leadership, and subordinate will produce corresponding emotional labor, which opened a research idea for us, and also can carry out a research direction in the future [33]. Hareli and Rafaeli think that, in interpersonal emotional process, the side of the emotional behavior may cause the other side's mood change, or will cause the other side to guess intent behind the emotional side, and to show the corresponding responses [34].

Although scholars have been talking about and making analysis on emotional labor integration, there is still lack of discussion and empirical research on the mediating mechanism. Based on the previous literature review, there are several intermediary mechanisms which may connect with the emotional labor between supervisors' and subordinates': Firstly, on the basis of study of Gardner et al., perceived sincerity may be one of the intermediary mechanism, because subordinates will take corresponding strategies of the emotional labor by judging the supervisors' emotional labor sincerity; Secondly, according to the social learning theory, due to supervisors' model effect, the supervisors are often regarded as subordinates' role models and learning objects, and subordinates will observe and imitate their supervisors' behavior and performance [35]. Therefore, subordinate may learn the ways of supervisors' emotional labor through social learning mechanism; Lastly, according to Lawler’s emotional social exchange theory, subordinates will make attribution of supervisors' emotional labor, find out the source, and then take corresponding emotional strategies. If subordinates are aware of surface acting of supervisors, they may produce negative feelings, and hide their true emotions by surface acting strategy [36]. However, the above three intermediary mechanisms still need to be further empirically researched by the scholars. Whether are there other intermediary mechanisms? Which intermediary mechanism is the most obvious? Whether do these intermediary mechanisms play a different role in the surface acting and the deep acting of emotional labor? Whether will there be cross effect between intermediary mechanisms? In addition, discussions of the above three kinds of intermediary mechanism are all standing in the perspective of subordinates. Does subordinates emotional labor behavior trigger corresponding emotional labor of supervisors? Will these mechanisms still apply? These issues are to be further studied in the future.

\section{References}

[1] Hochschild, A.R. (1993) Preface. In: Fineman, S., Ed., Emotion in Organization, Sage, London, 36-57.

[2] Humphrey, R.H., Pollack, J.M. and Hawver, T. (2008) Leading with Emotional Labor. Journal of Managerial Psychology, 23, 151-168. http://dx.doi.org/10.1108/02683940810850790

[3] Grandey, A.A. (2000) Emotional Regulation in the Workplace: A New Way to Conceptualize Emotional Labor. Journal of Occupational Health Psychology, 5, 95-110. http://dx.doi.org/10.1037/1076-8998.5.1.95

[4] Diefendorff, J.M. and Gosserand, R.H. (2003) Understanding the Emotional Labor Process: A Control Theory Perspective. Journal of Organizational Behavior, 24, 945-959. http://dx.doi.org/10.1002/job.230

[5] Wu, Z.Y. (2013) Emotional Labor Interaction between Supervisors and Subordinates: Review, Clarify and Foresight. Journal of Human Resource, 3, 57-105.

[6] Diefendorff, J.M., Croyle, M.H. and Gosserand, R.H. (2005) The Dimensionality and Antecedents of Emotional Labor Strategies. Journal of Vocational Behavior, 66, 339-357. http://dx.doi.org/10.1016/j.jvb.2004.02.001

[7] Hochschild, A.R. (1983) The Managed Heart: Commercialization of Human Feeling. University of California Press, Berkeley.

[8] Humphrey, R.H. (2008) The Right Way to Lead with Emotional Labor. In: Humphrey, R.H., Ed., Affect and Emotion: New Directions in Management Theory and Research, Information Age, Charlotte, 1-17.

[9] Wu, T.Y. and Hu, C. (2013) Abusive Supervision and Emotional Labor: Moderator Role of Openness. Journal of Applied Social Psychology, 43, 956-970. http://dx.doi.org/10.1111/jasp.12060

[10] Liu, C., Wang, H. and Wang, S.J. (2014) The Study of the Relationship between Leadership, Emotional Labor and Citizenship. China Soft Science, 3, 119-134.

[11] Liu, C. and Fan, J. (2014) The Supervisors' Influence of Emotional Labor for the Employee Organizational Identification Study. Financial Management and Practice, 5, 121-126. 
[12] (2013) Transformational Leadership and Emotional Labor Strategy: Intermediary Role of Job Involvement. Management at the Academic Edition, 9, 21-30.

[13] Barger, P.B. and Grandey, A.A. (2006) Service with a Smile and Encounter Satisfaction: Emotional Contagion and Appraisal Mechanism. Academy of Management Journal, 49, 1229-1238. http://dx.doi.org/10.5465/AMJ.2006.23478695

[14] Côté, S. (2005) A Social Interaction Model of the Effect of Emotion Regulation on Work Strain. Academy of Management Review, 30, 509-530. http://dx.doi.org/10.5465/AMR.2005.17293692

[15] Totterdell, P. and Holman, D. (2003) Emotion Regulation in Customer Service Roles: Testing a Model of Emotional Labor. Journal of Occupational Health Psychology, 8, 55-73.

[16] Morris, J.A. and Feldman, D.C. (1996) The Dimensions, Antecedents, and Consequences of Emotional Labor. Academy of Management Review, 21, 986-1010.

[17] Zhao, H.J. and Xi, Y.P. (2014) The Literature Review of Emotional Labor in Organizational Context. The Ninth Management Conference-The Paper of Organizational Behavior and Human Resource.

[18] Humphrey, R.H. (2012) How Do Leaders Use Emotional Labor? Journal of Organizational Behavior, 33, $740-744$. http://dx.doi.org/10.1002/job.1791

[19] Wu, Z.Y. (2008) The Intermediary Effect of Justice Perception and Emotional Labor in Emotional Exhaustion. The Chinese Journal of Psychology, 50, 201-221.

[20] Carlson, D., Ferguson, M., Hunter, E. and Whitten, D. (2012) Abusive Supervision and Work-Family Conflict: The Path through Emotional Labor and Burnout. The Leadership Quarterly, 23, 849-859. http://dx.doi.org/10.1016/j.leaqua.2012.05.003

[21] Chi, S.C.S. and Liang, S.G. (2012) When Do Subordinates' Emotion-Regulation Strategies Matter? Abusive Supervision, Subordinates' Emotional Exhaustion, and Work Withdrawal. The Leadership Quarterly, 24, 125-137. http://dx.doi.org/10.1016/j.leaqua.2012.08.006

[22] Hunt, J.G.J., Gardner, W.L. and Fischer, D. (2008) Leader Emotional Displays from Near and Far: Effects of Activation Potential and Valence. In: Humphrey, R.H., Ed., Affect and Emotion: New Directions in Management Theory and Research, Information Age, Charlotte, 43-65.

[23] Fisk, G.M. and Friesen, J.P. (2012) Perceptions of Leader Emotion Regulation and LMX as Predictors of Followers' Job Satisfaction and Organizational Citizenship Behaviors. The Leadership Quarterly, 23, 1-12. http://dx.doi.org/10.1016/j.leaqua.2011.11.001

[24] Wichroski, M.A. (1994) The Secretary: Invisible Labor in the Work World of Women. Human Organization, 53, 3341. http://dx.doi.org/10.17730/humo.53.1.a1205g53j7334631

[25] Lively, K.J. (2000) Reciprocal Emotion Management: Working Together to Maintain Stratification in Private Law Firms. Work and Occupations, 27, 32-63. http://dx.doi.org/10.1177/0730888400027001003

[26] Griffeth, R.W., Gaertner, S. and Sager, J.K. (2000) Taxonomic Model of Withdrawal Behaviors: The Adaptive Response Model. Human Resource Management Review, 9, 577-590. http://dx.doi.org/10.1016/S1053-4822(99)00034-0

[27] Grandey, A.A., Kern, J.H. and Frone, M.R. (2007) Verbal Abuse from Outsiders versus Insiders: Comparing Frequency, Impact on Emotional Exhaustion, and the Role of Emotional Labor. Journal of Occupational Health Psychology, 12, 63-79. http://dx.doi.org/10.1037/1076-8998.12.1.63

[28] Zheng, W.R. and Chen, C.X. (2012) Improper Supervision, Impression Management and Analysis of a Retreat: The Mediation Effect of Surface Performance and Deep Performance. Furen Management Review, 19, 1-28.

[29] Xu, J.Y. and Zan, J.Y. (2014) The Relationship between Authoritarian Leadership and Emotional Labor. Human Resource Management Review, 4, 31-55.

[30] Johnson, S.K., Murphy, S.E., Zewdie, S., et al. (2008) The Strong, Sensitive Type: Effects of Gender Stereotypes and Leadership Prototypes on the Evaluation of Male and Female Leaders. Organizational Behavior and Human Decision Processes, 106, 39-60. http://dx.doi.org/10.1016/j.obhdp.2007.12.002

[31] Gardner, W.L., Fischer, D. and Hunt, J.F. (2009) Emotional Labor and Leadership: A Threat to Authenticity? The Leadership Quarterly, 20, 466-482. http://dx.doi.org/10.1016/j.leaqua.2009.03.011

[32] Wu, Z.Y. and Liao, H.Y. (2013) Do Chinese Authoritarian Leaders Always Lead to Deployment of Negative Results. The Chinese Journal of Psychology, 1, 1-22.

[33] Epitropaki, O. (2006) “Leading the Show”: The Impact of Leader's Emotional Labor on Subordinates’ Transformational Leadership Perceptions and Collective Emotional Labor. Paper Presented at the Academy of Management.

[34] Hareli, S. and Rafaeli, A. (2008) Emotional Cycles: On the Social Influence of Emotion in Organizations. Research in Organizational Behavior, 28, 35-59. http://dx.doi.org/10.1016/j.riob.2008.04.007 
[35] Lian, H., Ferris, D.L. and Brown, D.J. (2012) Does Power Distance Exacerbate or Mitigate the Effects of Abusive Supervision? It Depends on the Outcomes. Journal of Applied Psychology, 97, 107-123.

http://dx.doi.org/10.1037/a0024610

[36] Lawler, E.J. (2001) Affect Theory of Social Exchange. The Academy Journal of Sociology, 107, 321-352.

http://dx.doi.org/10.1086/324071 